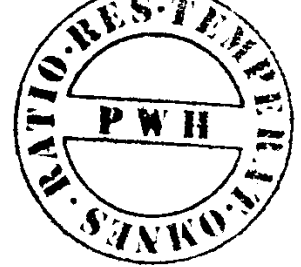

\title{
Pharmacokinetics of $\mathrm{Cl}$-inhibitor protein in patients with acute myocardial infarction
}

\begin{abstract}
Objectipes: CI-inhibitor protein (CI-INH) purified from pooled human plasma is used for the treatment of patients with hereditary angioedema. Recently, the beneficial effects of high-dose CI-INH treatment on myocardial ischemia or reperfusion injury have been reported in various animal models and in humans. We investigated the pharmacokinetic behavior of $\mathrm{Cl}-\mathrm{INH}$ in patients with acute myocardial infarction to calculate the amount of CI-INH required for optimal efficacy.

Metbods: Twenty-two patients received an intravenous loading dose, followed by 48 hours of continuous infusion of Cl-INH. Changes in the endogenous production of $\mathrm{Cl}-\mathrm{INH}$ were evaluated in 16 control patients with acute myocardial infarction. A 2 -compartment model was used to estimate the fractional catabolic rate constant (FCR), transcapillary escape rate constant (TER), and extravascular return rate constant (ERR) of Cl-INH. Software designed to analyze and fit measured data to unknown parameters in a system of differential equations was used to fit the experimental data against the 3-parameter model.

Results: With fixed TER and ERR values $\left(0.014 \mathrm{~h}^{-1}\right.$ and $0.018 \mathrm{~h}^{-1}$, respectively), 20 of the 22 cases yielded well-determined FCR values, and simultaneous fitting resulted in a median FCR of $0.011 \mathrm{~h}^{-1}\left(95 \% \mathrm{confi}^{-}\right.$ dence interval, 0.010 to $0.012 \mathrm{~h}^{-1}$ ) versus $0.025 \mathrm{~h}^{-1}$ as reported in healthy control patients. Simultaneous estimation of TER, ERR, and FCR demonstrated weakly defined TER and ERR values, whereas the median FCR value remained unchanged. The use of a 2 -compartment model resulted in a significantly better fit compared with the 1-compartment model. Physiologic explanations are offered for discrepancies in the literature.

Conclusions: Dose calculation of Cl-INH in patients treated with massive doses of Cl-INH requires turnover parameters that differ from those found in healthy subjects, possibly because of suppression of continuous CI-INH consumption by target proteases. (Clin Pharmacol Ther 2002;72:498-504.)
\end{abstract}

Jart H. C. Diris, MSc, Wim Th. Hermens, PhD, Pieter W. Hemker, PhD, Wim K. Lagrand, PhD, C. Erik Hack, PhD, and Marja P. van Dieijen-Visser, PhD Maastricht and Amsterdam, The Netherlands

C1-inhibitor protein (C1-INH), a protein of approximately $104 \mathrm{kd}$, regulates the classical activation pathway of the complement system. ${ }^{1}$ Patients with hereditary angioedema (HAE), in whom there is a congenital

From the Department of Clinical Chemistry, University Hospital Maastricht, and Cardiovascular Research Institute Maastricht, University of Maastricht, Maastricht; and National Research Institute for Mathematics and Computer Science; Department of Cardiology, Institute for Cardiovascular Research, and Department of Clinical Chemistry, Vrije Universiteit Medical Center; and Sanquin Research, Amsterdam.

Received for publication Dec 12, 2001; accepted June 18, 2002.

Reprint requests: Jart H. C. Diris, MSc, Department of Clinical Chemistry, University Hospital Maastricht, PO Box 5800, 6202 AZ Maastricht, The Netherlands.

E-mail: J.Diris@groupwise.azm.nl

Copyright (1) 2002 by the American Society for Clinical Pharmacology \& Therapeutics.

$0009-9236 / 2002 / \$ 35.00+0 \quad 13 / 1 / 129320$

doi: $10.1067 / \mathrm{mcp} .2002 .129320$ lack of C1-INH, have attacks of uncontrolled complement activation that may lead to life-threatening laryngeal obstruction or swelling of the gastrointestinal mucosa. $^{2}$ Depending on the severity of the edematous attack, treatment of patients with HAE usually consists of one or more bolus injections of $\mathrm{Cl}$-INH purified from pooled human plasma.

Other diseases in which complement inhibition might have beneficial effects are being explored, and the administration of $\mathrm{Cl}$-INH has been investigated in patients with sepsis, ${ }^{1}$ rheumatoid arthritis, ${ }^{3}$ and B-cell lymphoproliferative disorders. ${ }^{4}$ Recent studies in various animal models have shown reduction of myocardial ischemia or reperfusion injury after high-dose C1-INH therapy. ${ }^{5-8}$ To investigate the effects of C1-INH in patients with acute myocardial infarction, we recently performed a dose-escalating pilot study. ${ }^{9}$ Patients were given an initial loading dose of $\mathrm{C} 1-\mathrm{INH}$, followed by 
continuous infusion during the next 48 hours. Complement inhibition in this study proved to be strongly dose-dependent and necessitated accurate C1-INH dosage control. However, C1-INH was apparently eliminated more slowly than expected from available data of patients with HAE. Therefore we decided to study the pharmacokinetics of $\mathrm{Cl}-\mathrm{INH}$ in patients with acute myocardial infarction receiving high doses of this inhibitor.

\section{METHODS}

Twenty-two patients ( 12 men and 10 women; median age, 60.5 years) with acute myocardial infarction were admitted to the Intensive Coronary Care Unit, University Hospital Maastricht, The Netherlands. After informed consent was obtained for patients to participate in an open-label pilot study, treatment with $\mathrm{C} 1-\mathrm{INH}$ was started 6 hours after the onset of symptoms by means of 3 different dosage schemes as follows: an initial loading dose of $50 \mathrm{U} / \mathrm{kg}$ body weight, followed by a continuous infusion of $1.25 \mathrm{U} \cdot \mathrm{kg}^{-1} \cdot \mathrm{h}^{-1}$; an initial loading dose of $100 \mathrm{U} / \mathrm{kg}$ body weight, followed by a continuous infusion of $1.25 \mathrm{U} \cdot \mathrm{kg}^{-1} \cdot \mathrm{h}^{-1}$; or an initial loading dose of $100 \mathrm{U} / \mathrm{kg}$ body weight, followed by a continuous infusion of $2.00 \mathrm{U} \cdot \mathrm{kg}^{-1} \cdot \mathrm{h}^{-1}$ during the next 48 hours. Loading doses were infused at a rate of $250 \mathrm{U} / \mathrm{min}$. The administered amounts were chosen in an effort to reach concentrations between $200 \%$ and $300 \%$ of normal. No presumptions were made about reaching steady-state conditions. C1-INH (Cetor; CLB, Amsterdam, The Netherlands) was purified (>95\%) from human plasma according to good manufacturer's practice guidelines and was tested for viral safety and clinical efficacy. The lyophilized protein was reconstituted in water before administration.

Blood samples were collected before administration of the loading dose and at $1,3,6,9,12,15,18,24,36$, 48 , and 72 to 96 hours after the start of loading dose administration. Clotting was prevented with ethylenediaminetetraacetic acid (EDTA), and plasma samples obtained by immediate routine centrifugation were stored at $-70^{\circ} \mathrm{C}$ until further analysis.

Changes in endogenous $\mathrm{Cl}$-INH production after acute myocardial infarction were assessed by measuring the course of plasma $\mathrm{C} 1-\mathrm{INH}$ in 16 control patients with acute myocardial infarction who did not receive C1-INH. These patients were admitted to the Department of Cardiology, VU University Medical Center, Amsterdam, The Netherlands. ${ }^{10}$ Blood samples were collected at admission and at 2, 6, 12, 24, 36, 48, 60, and 72 hours thereafter. After centrifugation, plasma

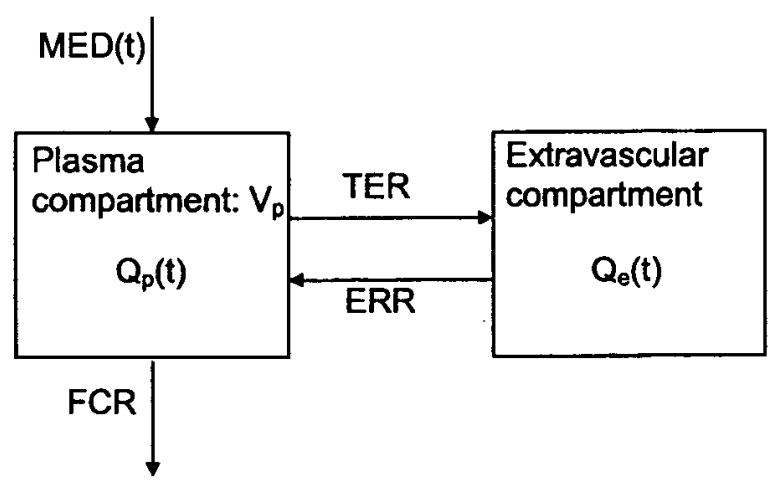

Fig 1. Two-compartment model. $Q_{p}(t)$, Amount of $C 1$ inhibitor (C1-INH) in plasma (in units) at time $t ; Q_{e}(t)$, amount of extravascular $\mathrm{C} 1$-INH (in units) at time $t ; \mathrm{V}_{\mathrm{p}}$, plasma volume; Med(t), input function of C1-INH; TER, transcapillary escape rate constant; ERR, extravascular return rate constant; FCR, fractional catabolic rate constant.

was collected and stored in aliquots at $-70^{\circ} \mathrm{C}$ until assays were performed.

C1-INH concentrations were determined with the use of a commercially available functional assay based on a chromogenic assay (Berichrom $\mathrm{Cl}$ inhibitor assay; Behringwerke AG, Marburg, Germany). Values were expressed in units per liter, with 1 unit equal to the activity of $\mathrm{Cl}-\mathrm{INH}$ in $1 \mathrm{~mL}$ of pooled plasma obtained from healthy donors. The specific activity of C1-INH was $3.8 \mathrm{U} / \mathrm{mg}$ protein.

A 2-compartment model, as described in Fig 1, was used to estimate individual pharmacokinetic parameters of C1-INH. Time-related changes in plasma and extravascular C1-INH pools are given by the following equations:

$$
\begin{aligned}
\mathrm{dQ}_{\mathrm{p}}(\mathrm{t}) / \mathrm{dt}= & M E D(\mathrm{t})-(\mathrm{FCR}+\mathrm{TER}) \times \mathrm{Q}_{\mathrm{p}}(\mathrm{t}) \\
& +\mathrm{ERR} \times \mathrm{Q}_{\mathrm{e}}(\mathrm{t}) \\
\mathrm{dQ}_{\mathrm{e}}(\mathrm{t}) / \mathrm{dt}= & \text { TER } \times \mathrm{Q}_{\mathrm{p}}(\mathrm{t})-\mathrm{ERR} \times \mathrm{Q}_{\mathrm{e}}(\mathrm{t})
\end{aligned}
$$

in which $Q_{p}(t)$ and $Q_{e}(t)$ are the plasma and extravascular pools, respectively, expressed in units at time $t$, $\operatorname{MED}(t)$ is the input function of $\mathrm{C1}-\mathrm{INH}, \mathrm{FCR}$ is the fractional catabolic rate constant (per hour) for the elimination of C1-INH from the plasma, TER is the transcapillary escape rate constant (per hour) of $\mathrm{C} 1$ INH for extravasation of C1-INH to the extravascular compartment, and ERR is the extravascular return rate constant (per hour) for the return of $\mathrm{C} 1-\mathrm{INH}$ from the extravascular compartment to plasma.

Equation 2, used as an initial condition, presents steady-state conditions for the amount of $\mathrm{C1}$-INH in the extravascular compartment at time $0 . Q_{p}(0)$ is known 


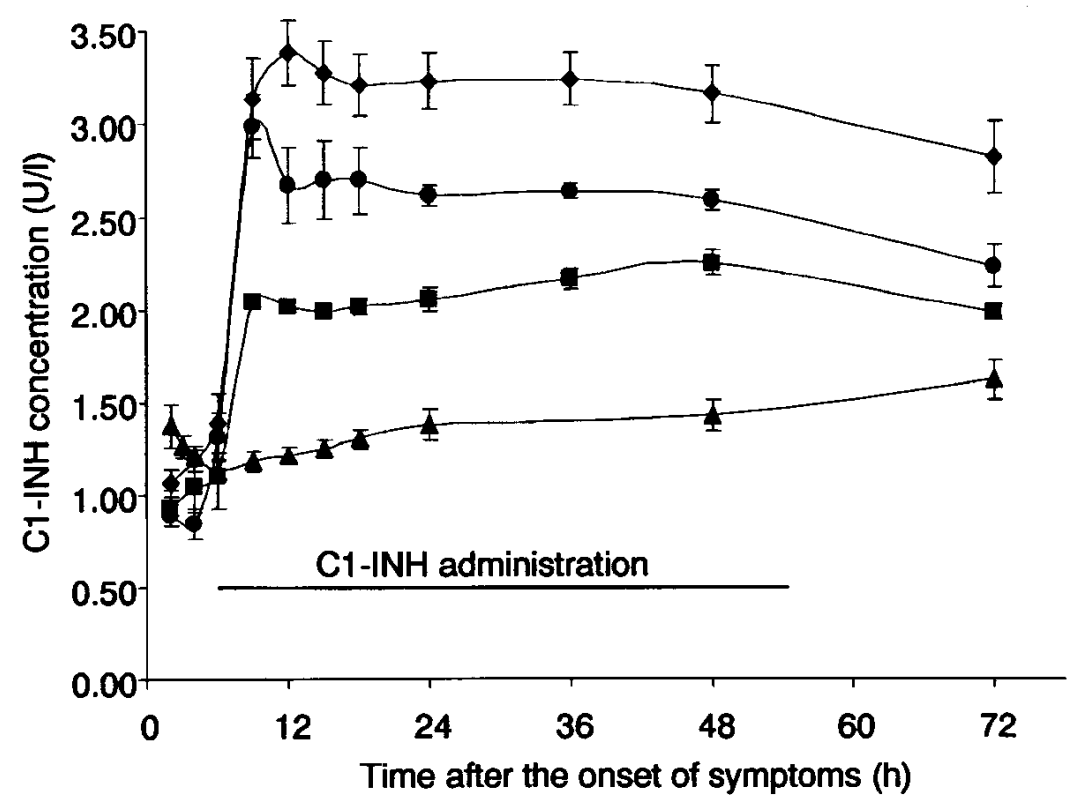

Fig 2. C1-INH plasma curves of 3 infusion groups and control patients (mean with standard error). Group 1 (squares): Loading dose, $50 \mathrm{U} / \mathrm{kg}$; infusion rate, $1.25 \mathrm{U} \cdot \mathrm{kg}^{-1} \cdot \mathrm{h}^{-1}(\mathrm{n}=6)$. Group 2 (circles): Loading dose, $100 \mathrm{U} / \mathrm{kg}$; infusion rate, $1.25 \mathrm{U} \cdot \mathrm{kg}^{-1} \cdot \mathrm{h}^{-1}(\mathrm{n}=5$ ). Group 3 (diamonds): Loading dose, $100 \mathrm{U} / \mathrm{kg}$; infusion rate, $2.00 \mathrm{U} \cdot \mathrm{kg}^{-1} \cdot \mathrm{h}^{-1}(\mathrm{n}=11)$. Control patients (triangles): No C1-INH administered $(n=16)$.

by measurement of the $\mathrm{C} 1$-INH plasma concentration at time 0 (ie, before C1-INH administration).

$$
\mathrm{Q}_{e}(0)=[\mathrm{TER} / \mathrm{ERR}] \times \mathrm{Q}_{\mathrm{p}}(\mathbf{0})
$$

All plasma concentrations were converted to total amounts in units by multiplying the concentrations in units per liter by the individual plasma volume in liters. Plasma volume was calculated from the initial increase in C1-INH concentration after administration of the loading dose.

A software package called spIds, ${ }^{11}$ developed for estimation of unknown parameters in time-dependent dynamic systems, ${ }^{12}$ was used to solve the system defined by the differential algebraic equations $l a$ and $\mathrm{lb}$ and the initial condition given by equation 2 . It uses the algebra package Maple V (Waterloo Maple Inc, Ontario, Canada) to derive variational equations from the differential equations. These variational equations are then used in the process by combining them with the initial differential equations. The Levenberg-Marquardt method was used to minimize the total sum of squared discrepancies between calculated and measured values of $Q_{\mathrm{p}}$. A confidence interval (CI) at a user-defined level $\alpha$ (ie, .05) is calculated for each estimate. The program also gives a detailed analysis of the reliability and interdependencies of the parameters. This is used to evaluate whether each parameter independently contributes to a significant decrease in the total sum of squares. Thus we can verify whether the use of a 2-compartment model is to be preferred over a 1-compartment model.

\section{RESULTS}

Fig 2 shows mean plasma $\mathrm{C} 1$-INH concentrations for the 3 patient groups with different dosage schemes and for the control patients. A clear dose-concentration profile is visible in the 3 groups that received $\mathrm{C} 1-\mathrm{INH}$ therapy. A decrease in C1-INH is shown in the group of control patients in the first 6 hours after the onset of symptoms, and a slow but continuing increase in $\mathrm{C} 1$ INH concentration after 6 hours can be noted in the same group.

Fig 3 demonstrates the mean observed and fitted C1-INH plasma concentration curves, as well as the calculated extravascular C1-INH pool, for each dosage group. After a rapid increase caused by the loading dose, a plateau phase is visible for the duration of the infusion. When the infusion was stopped, a gradual decline in the plasma concentration was seen, while the extravascular pool continued to increase, albeit with diminishing speed. The latter finding indicates that no steady-state conditions were reached. 

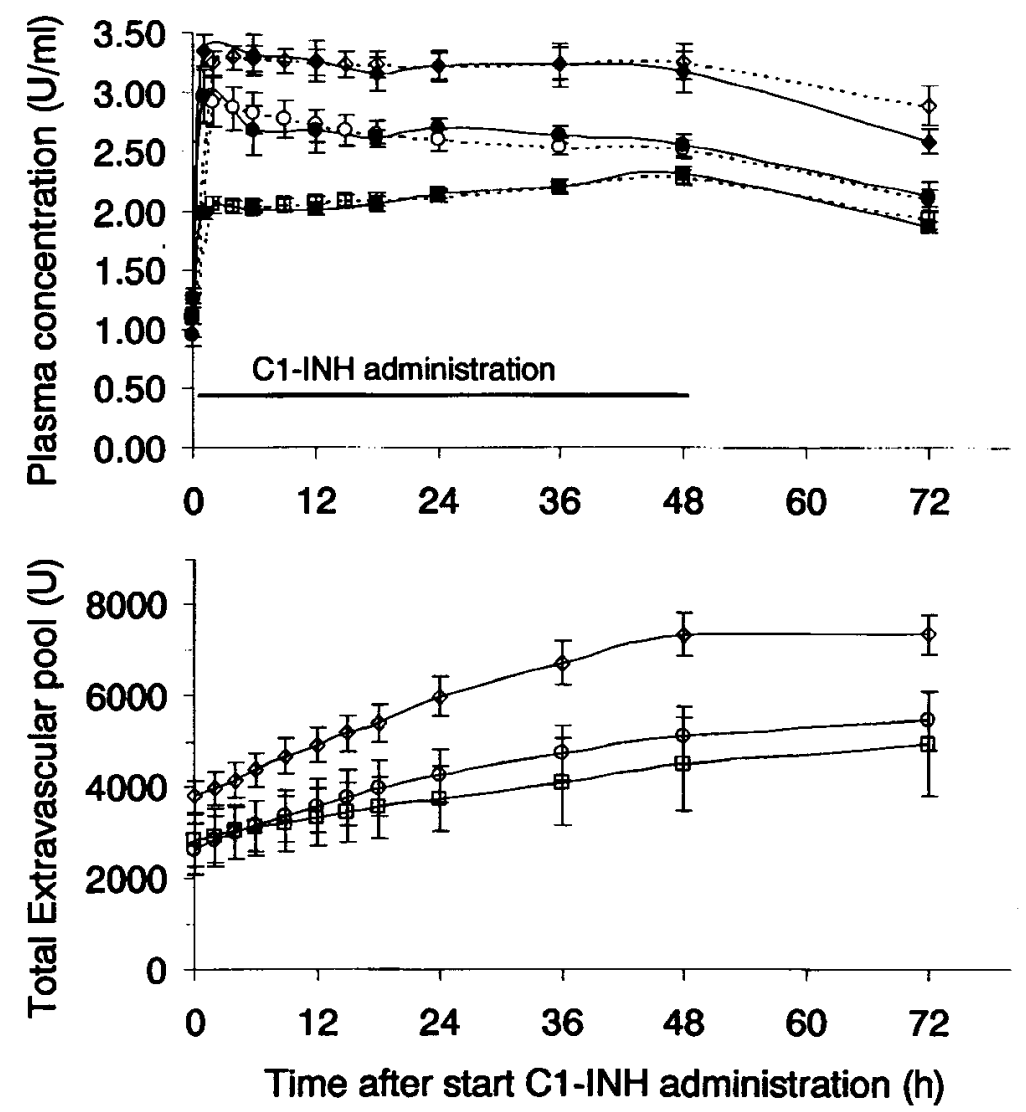

Fig 3. Time course of C1-INH plasma concentration and extravascular content after treatment (mean with standard error [ $\mathrm{n}=22]$ ). Upper panel, Plasma concentrations (in units per milliliter) in group 1 (squares), group 2 (circles), and group 3 (diamonds). Solid lines, Measured C1-INH plasma concentrations; dotted lines, fitted C1-INH plasma concentrations. Lower panel, Calculated extravascular C1-INH pool (in units) in group 1 (squares), group 2 (circles), and group 3 (diamonds).

On the basis of plausible fixed TER and ERR values $\left(0.014 \mathrm{~h}^{-1}\right.$ and $0.018 \mathrm{~h}^{-1}$, respectively; see Discussion section), the FCR for individual patients was estimated. The results listed in Table I demonstrate that 20 of the 22 cases had well-determined FCR values, with CIs of less than $55 \%$. The 2 cases with CIs greater than $100 \%$ both underwent sampling for only a short period of time ( $<30$ hours) because of difficulties with blood sampling (not drug-related). Simultaneous fitting of the remaining 20 patients with fixed TER and ERR values yielded the same FCR as the calculated median $(0.011$ $\mathbf{h}^{-1}$ ), but this value was better defined (Table I).

Estimation of all 3 parameters resulted in almost the same FCR value, $0.012 \mathrm{~h}^{-1}$ (CI, 0.002 to $0.022 \mathrm{~h}^{-1}$ ). The TER and ERR values were $0.021 \mathrm{~h}^{-1}(\mathrm{CI},-0.018$ to $0.060 \mathrm{~h}^{-1}$ ) and $0.019 \mathrm{~h}^{-1}$ (CI, -0.055 to $0.093 \mathrm{~h}^{-1}$ ), respectively, but the large $\mathrm{CIs}$ indicate that no precise TER and ERR values could be determined.

\section{DISCUSSION \\ Recovery of C1-INH}

From the plasma volumes and individual body weights listed in Table I, a median plasma volume of 48 $\mathrm{mL} / \mathrm{kg}$ body weight was calculated. Comparison with the normal plasma value of $41 \mathrm{~mL} / \mathrm{kg}$ (corrected for sex, weight, and age $)^{13}$ showed an apparent incomplete recovery $(85 \%)$ of $\mathrm{C} 1-\mathrm{INH}$, probably caused by consumption of $\mathrm{C} 1-\mathrm{INH}$ in the acute phase. This finding is supported by the initial decrease in C1-INH in control patients (Fig 2).

\section{Validation of model used}

On the basis of the independency of the parameters (data not shown), adding a second compartment to the model caused a significant reduction in the total sum of squares. This means that, although the data obtained lack extravascular measurements, the use of a 
Table I. Results of 2-compartment model on patients with acute myocardial infarction

\begin{tabular}{cccccl}
\hline Patient no. & Sex & Age $(y)$ & Body weight $(\mathrm{kg})$ & $V_{\boldsymbol{p}}(\mathrm{mL})$ & FCR and $95 \% C I\left(\mathrm{~h}^{-1}\right)^{*}$ \\
\hline 1 & $\mathrm{~F}$ & 74 & 75 & 2953 & $0.009(0.005$ to 0.013$)$ \\
2 & $\mathrm{M}$ & 51 & 107 & 5144 & $0.009(0.008$ to 0.010$)$ \\
3 & $\mathrm{M}$ & 60 & 85 & 4474 & $0.007(0.005$ to 0.009$)$ \\
4 & $\mathrm{M}$ & 58 & 105 & 4953 & $0.005(0.003$ to 0.007$)$ \\
$5 \dagger$ & $\mathrm{F}$ & 55 & 55 & 2500 & $0.900(-0.470$ to 2.270$)$ \\
6 & $\mathrm{~F}$ & 38 & 71 & 3170 & $0.011(0.010$ to 0.012$)$ \\
7 & $\mathrm{M}$ & 61 & 88 & 3411 & $0.012(0.009$ to 0.015$)$ \\
8 & $\mathrm{~F}$ & 46 & 60 & 2970 & $0.003(0.002$ to 0.004$)$ \\
9 & $\mathrm{~F}$ & 70 & 56 & 2857 & $0.011(0.008$ to 0.014$)$ \\
10 & $\mathrm{M}$ & 57 & 75 & 5068 & $0.010(0.005$ to 0.015$)$ \\
11 & $\mathrm{M}$ & 40 & 78 & 3000 & $0.021(0.017$ to 0.025$)$ \\
12 & $\mathrm{M}$ & 51 & 80 & 4420 & $0.010(0.006$ to 0.014$)$ \\
13 & $\mathrm{M}$ & 63 & 70 & 3784 & $0.017(0.012$ to 0.022$)$ \\
14 & $\mathrm{~F}$ & 83 & 64 & 2795 & $0.016(0.014$ to 0.018$)$ \\
15 & $\mathrm{~F}$ & 78 & 73 & 3106 & $0.016(0.011$ to 0.021$)$ \\
16 & $\mathrm{M}$ & 59 & 58 & 3590 & $0.025(0.021$ to 0.029$)$ \\
$17 \dagger$ & $\mathrm{F}$ & 74 & 100 & 2929 & $0.002(-0.004$ to 0.008$)$ \\
18 & $\mathrm{M}$ & 61 & 82 & 6329 & $0.017(0.010$ to 0.024$)$ \\
19 & $\mathrm{M}$ & 61 & 93 & 4059 & $0.007(0.004$ to 0.010$)$ \\
20 & $\mathrm{M}$ & 68 & 96 & 4769 & $0.009(0.007$ to 0.011$)$ \\
21 & $\mathrm{~F}$ & 57 & 87 & 3254 & $0.012(0.005$ to 0.019$)$ \\
22 & F & 68 & 77 & 3750 & $0.011(0.009$ to 0.013$)$ \\
Median $(\mathrm{n}=20)$ & & 60.5 & 3500 & $0.011(0.008$ to 0.014$)$ \\
\hline
\end{tabular}

$\mathrm{V}_{\mathrm{P}}$, Plasma volume; FCR, fractional catabolic rate constant; $\mathrm{CI}$, confidence interval; F, female; $M$, male.

*Simultaneous fit of 20 patients (fixed transcapillary escape rate constant $\left[0.014 \mathrm{~h}^{-1}\right]$ and extravascular return rate constant $\left.\left[0.018 \mathrm{~h}^{-1}\right]\right): \mathrm{FCR}^{2}=0.011 \mathrm{~h}^{-1}(95 \% \mathrm{CI}$, 0.010 to $0.012 \mathrm{~h}^{-1}$ ). Individual fit of 20 patients (estimation of all 3 parameters): $\mathrm{FCR}=0.012 \mathrm{~h}^{-1}\left(95 \% \mathrm{Cl}, 0.002\right.$ to $0.022 \mathrm{~h}^{-1}$ ).

$\dagger$ Sampling period $<30$ hours; therefore patient's data were excluded from calculations.

2-compartment model still results in a better fit of the plasma curves compared with a 1-compartment model.

\section{TER and ERR values}

The choice of plausible fixed values for TER $(0.014$ $\left.\mathrm{h}^{-1}\right)$ and ERR $\left(0.018 \mathrm{~h}^{-1}\right)$ in this study was based on an overview of data on the behavior of circulating proteins in humans. ${ }^{14}$ These data, in most cases obtained from turnover studies of radiolabeled proteins, show an average extravasation rate of about $1.4 \%$ of the plasma pool per hour for proteins with a molecular weight exceeding $100 \mathrm{kd}$. Moreover, it was found that the extravascular pool of such proteins is somewhat smaller than the plasma pool, as also follows from the equilibrium relation $\mathrm{E} / \mathrm{P}=\mathrm{TER} / \mathrm{ERR}=0.78$, where $\mathrm{E} / \mathrm{P}$ is the extravascular pool/plasma pool ratio.

The fact that no precise TER and ERR values for C1-INH could be determined is mainly caused by the lack of extravascular measurements. The small number of observations ( 2 or 3 ) made after the end of infusion enlarges the imprecision of TER and ERR because it is primarily this last part of the plasma curve that expresses these values.

\section{Estimation of FCR: Comparison with data from literature}

Table II presents an overview of C1-INH turnover studies in healthy subjects and in patients with various diseases. Apart from this study, all studies used single intravenous bolus injections of C1-INH. With the exception of the study of Kunschak et al, ${ }^{15}$ in which the total observation time was limited to 24 hours, C1-INH concentrations were measured for at least 72 hours.

In a number of these studies ${ }^{15-17}$ the apparent disappearance rate constant $\left(k_{d}\right)$ rather than the true fractional catabolic rate constant for the disappearance of C1-INH from plasma was determined. For instance, Brackertz et $\mathrm{al}^{16}$ found a biphasic disappearance of injected C1-INH in control subjects and reported a plasma half-life of 64 hours for the final slow disappearance phase from 3 to 8 days after injection. However, the corresponding apparent disappearance rate constant $k_{d}=(\ln 2) / 64=0.011 h^{-1}$ also incorporates the return of extravascular C1-INH to plasma, which suggests that the FCR would be even lower than 0.011 $h^{-1}$.

Another situation occurred in the study of Kunschak 
Table II. Data from literature on human $\mathrm{Cl}$ inhibitor turnover

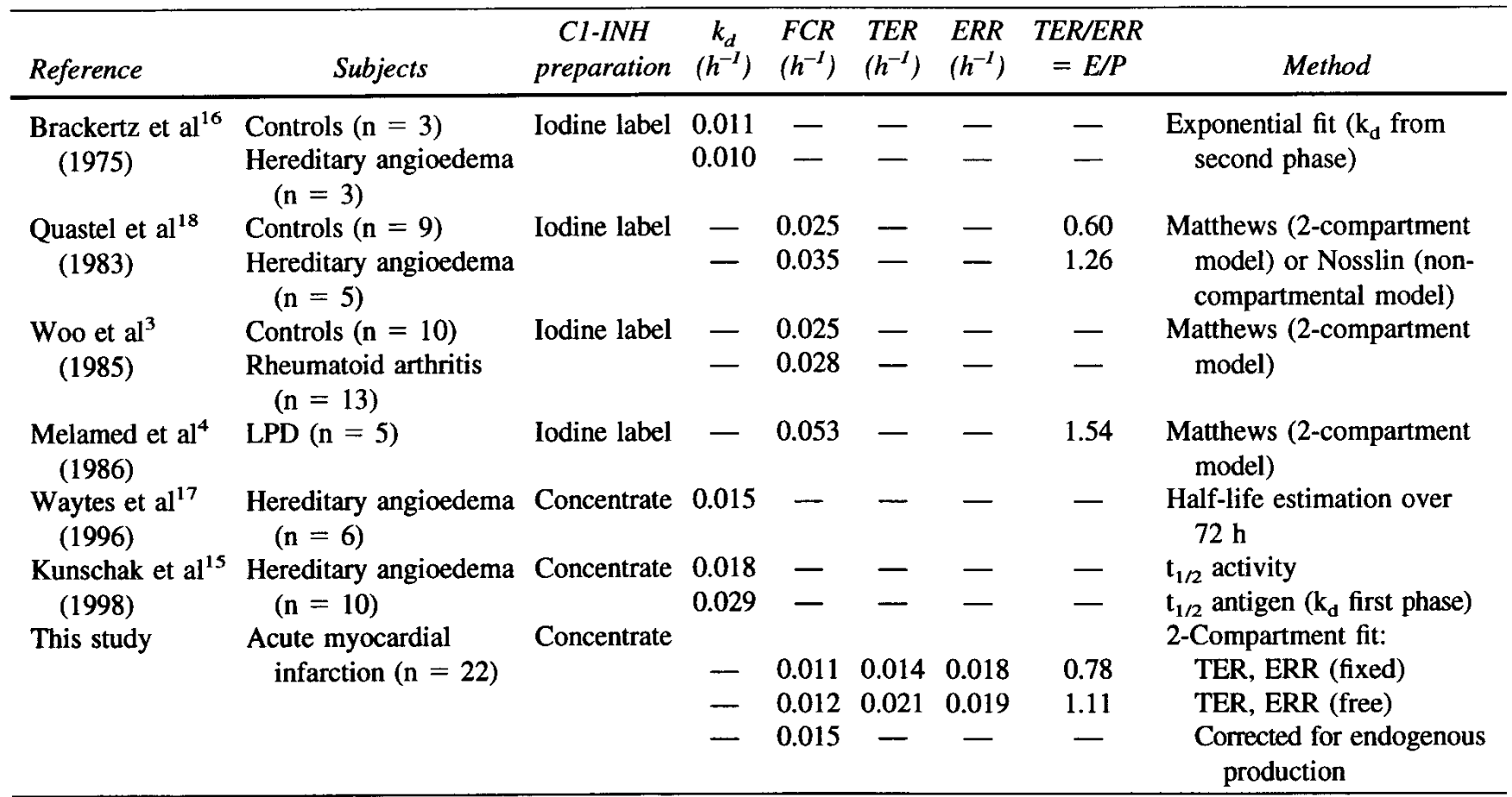

$\mathrm{Cl}$-INH, $\mathrm{Cl}$ inhibitor; $\mathbf{k}_{\mathrm{d}}$, apparent disappearance rate constant; TER, transcapillary escape rate constant; ERR, extravascular return rate constant; E/P, extravascular pool/plasma pool; LPD, lymphoproliferative disorder; $t_{1 / 2}$, half-life.

et al, ${ }^{15}$ who reported half-lives of 37.8 to 24.0 hours for the initial disappearance phase of C1-INH in patients with $\mathrm{HAE}$, corresponding to $\mathrm{k}_{\mathrm{d}}$ values of 0.018 to 0.029 $\mathrm{h}^{-1}$. These values are indeed higher than the true FCR, because C1-INH is not only catabolized but also extravasating during the first 24 hours after a bolus injection.

Overall, Table II shows that an FCR value of 0.025 $\mathrm{h}^{-1}$ was obtained in healthy subjects and that higher values are obtained in patients with various diseases that cause consumption of C1-INH as a result of complement activation, such as $\mathrm{HAE}$, rheumatoid arthritis, and various forms of leukemia.

\section{Possible explanations for discrepancies in FCR values}

A first explanation for the relatively low FCR value could be a considerable increase in endogenous production of C1-INH in the days after acute myocardial infarction. Such acute phase reactant-like behavior of C1-INH could compensate for the extra consumption of C1-INH as a result of complement activation during the first 24 hours after acute myocardial infarction. However, the course of C1-INH plasma levels in the control patients did not support this explanation, given that levels initially decreased rather than increased (Fig 2), suggesting increased consumption and not increased synthesis.

Furthermore, increased endogenous production of acute phase reactants usually starts after more than 24 hours, and Fig 2 indeed shows that C1-INH plasma concentrations in control patients are increasing slightly in the days after acute myocardial infarction. On the basis of data from these patients, it was estimated that this slow increase corresponded to an average increase in $\mathrm{C} 1-\mathrm{INH}$ synthesis of $17 \mathrm{U} / \mathrm{h}$. When this production was added to equation la, it was found that the FCR changed only marginally to $0.015 \mathrm{~h}^{-1}$ (CI, 0.013 to $0.017 \mathrm{~h}^{-1}$ ) (Table II).

Another explanation for the discrepancy between healthy subjects and patients with acute myocardial infarction could be that continuous consumption of C1-INH caused by complex formation with activated proteases and subsequent rapid removal of complexes from plasma is a main determinant of C1-INH elimination in healthy subjects. If it is assumed that the disappearance of functional $\mathrm{C} 1-\mathrm{INH}$ proceeds via 2 almost equally contributing pathways, (1) inactivation resulting from complex formation and (2) slow hepatic removal of C1-INH with an FCR value of about 0.011 $\mathrm{h}^{-1}$, it is clear that in studies that used lower doses the 
combination of 2 removal pathways could be mistaken for a higher FCR value.

An obvious difference between the other studies mentioned in Table II and this study is that we used bulk amounts of C1-INH instead of trace amounts of radiolabeled $\mathrm{C} 1-\mathrm{INH}$. Patients with $\mathrm{HAE}$ are usually treated with doses of $1000 \mathrm{U}$. In contrast, the patients with acute myocardial infarction in this study received total doses of as much as $20,000 \mathrm{U}$. At these high doses, disappearance as a result of complex formation will play only a relatively minor role, as compared with hepatic removal of functional C1-INH. This could reveal the observed FCR value of $0.011 \mathrm{~h}^{-1}$.

A similar low FCR value was found by Quastel et $\mathrm{al}^{18}$ for a dysfunctional C1-INH protein, Ta. They reported that $\mathrm{C} 1-\mathrm{INH}$ Ta scarcely binds to $\mathrm{C} 1$. This too supports the idea of the important role of continuous C1-INH disappearance from plasma as a result of complex formation. The defective complex formation of Ta blocked one of the two pathways, thus decreasing the speed of disappearance and revealing the true FCR.

In conclusion, pharmacokinetic data for $\mathrm{C} 1-\mathrm{INH}$ were estimated in patients with acute myocardial infarction receiving high doses of this inhibitor. The obtained FCR value $\left(0.011 \mathrm{~h}^{-1}\right)$ is lower than that previously found $\left(0.025 \mathrm{~h}^{-1}\right)$. Saturation of the normal steady-state kinetics of $\mathrm{C} 1$-INH may explain this finding. These data may help to design further clinical trials with this anti-inflammatory drug.

We thank Apple Kleine for collecting patient data, Wim Bleeker for his useful suggestions, and the Technology Foundation for the use of the program spIds. Special thanks to Walter Stortelder for his valuable knowledge about programmatic details of spIds and Jan Kok for his lessons in using this program.

\section{References}

1. Caliezi C, Wuillemin WA, Zeerleder S, Redondo M, Eisele B, Hack CE. C1-esterase inhibitor: an antiinflammatory agent and its potential use in the treatment of diseases other than hereditary angioedema. Pharmacol Rev 2000;52:91-112.

2. Bork K, Barnstedt SE. Treatment of 193 episodes of laryngeal edema with $\mathrm{C} 1$ inhibitor concentrate in patients with hereditary angioedema. Arch Intern Med 2001;161: 714-8.

3. Woo P, Lachmann PJ, Harrison RA, Amos N, Cooper C, Rosen FS. Simultaneous turnover of normal and dysfunctional $\mathrm{C} 1$ inhibitor as a probe of in vivo activation of $\mathrm{Cl}$ and contact activatable proteases. Clin Exp Immunol 1985;61:1-8.

4. Melamed J, Alper CA, Cicardi M, Rosen FS. The metabolism of $\mathrm{C}$ ! inhibitor and $\mathrm{Clq}$ in patients with ac- quired C1-inhibitor deficiency. J Allergy Clin Immunol 1986;77:322-6.

5. Murohara T, Guo JP, Delyani JA, Lefer AM. Cardioprotective effects of selective inhibition of the two complement activation pathways in myocardial ischemia and reperfusion injury. Methods Find Exp Clin Pharmacol 1995; 17:499-507.

6. Buerke M, Murohara T, Lefer AM. Cardioprotective effects of a C1-esterase inhibitor in myocardial ischemia and reperfusion. Circulation 1995;91:393-402.

7. Horstick G, Heimann A, Gotze O, Hafner G, Berg O, Boehmer $\mathbf{P}$, et al. Intracoronary application of $\mathrm{Cl}$ esterase inhibitor improves cardiac function and reduces myocardial necrosis in an experimental model of ischemia and reperfusion. Circulation 1997;95:701-8.

8. Kleine A, Muller-Boumans M-L, Kop-Klaassen B, Koenderman A, Hack E, Hermens W. Cardioprotective effects of C1-inhibitor after coronary occlusion in dogs: comparison of effects in reperfused and non-reperfused hearts [abstract]. Eur Heart J 2000;21:78.

9. Diris J, Kleine A, Zwaan C, Hack C, Tissing M, Strengers $\mathrm{P}$. Beneficial effects of $\mathrm{Cl}$-inhibitor treatment in patients with acute myocardial infarction [abstract]. Clin Chem Lab Med 2001;39:S183.

10. Lagrand WK. C-reactive protein and related inflammatory mediators in acute and chronic ischemic myocardial syndromes. Amsterdam: Free Univ. of Amsterdam; 2001.

11. Everaars C, Hemker P, Stortelder P. Manual of SPLDs, a software package for parameter identification in dynamic systems. Amsterdam: National Research Institute for Mathematics and Computer Science; 1995.

12. Stortelder W. Parameter estimation in dynamic systems. Math Comput Simul 1996;42:135-42.

13. Dagher FJ, Lyons JH, Finlayson DC, Shamsai J, Moore FD. Blood volume measurement: a critical study prediction of normal values: controlled measurement of sequential changes: choice of a bedside method. Adv Surg 1965;1:69-109.

14. Hermens WT, Willems GM, Visser MP. Quantification of circulating proteins. Boston: Martinus Nijhoff; 1982.

15. Kunschak M, Engl W, Maritsch F, Rosen FS, Eder G, Zerlauth G, et al. A randomized, controlled trial to study the efficacy and safety of $\mathrm{Cl}$ inhibitor concentrate in treating hereditary angioedema. Transfusion 1998;38: 540-9.

16. Brackertz D, Isler E, Kueppers F. Half-life of C1INH in hereditary angioneurotic oedema (HAE). Clin Allergy 1975;5:89-94.

17. Waytes AT, Rosen FS, Frank MM. Treatment of hereditary angioedema with a vapor-heated $\mathrm{C} 1$ inhibitor concentrate. N Engl J Med 1996;334:1630-4.

18. Quastel M, Harrison R, Cicardi M, Alper CA, Rosen FS. Behavior in vivo of normal and dysfunctional $\mathrm{Cl}$ inhibitor in normal subjects and patients with hereditary angioneurotic edema. J Clin Invest 1983;71:1041-6. 